\title{
Methodological Implications of Critical Realism for Entrepreneurship Research
}

\author{
Dr. Xiaoti Hu \\ Faculty of Business and Law, University of Portsmouth \\ Richmond Building, Portland Street, Portsmouth, PO1 3DE \\ Email: Xiaoti.hu@port.ac.uk
}

\begin{abstract}
Few papers have offered clear guidance for the application of CR to empirical studies, particularly in the research field of entrepreneurship. The purpose of this paper is to critically review how the methodological principles used to conduct CR-based research can be applied in empirical studies and to develop a critical realist case study research design to guide empirical work in entrepreneurship. Specifically, I examine the core ontological assumptions and methodological implications of CR, and illustrate how these shape our logic of inference in research methodology known as retroduction. I demonstrate the value of a CR-informed approach in empirical studies by drawing on a qualitative case study that explains the reality of entrepreneurial opportunities. My inclusion of the three domains of reality and various data analysis techniques within the process of conceptual abstraction and retroduction contributes a distinctive methodological development in this field, which illustrates how CR can work in an applied setting to explain competing theories. I argue that such a research design enables us to conduct empirical studies and provide comprehensive causal explanations of complex social events.
\end{abstract}

Key words: critical realism, abstraction, retroduction, research design, methodology, entrepreneurship, opportunity 


\section{Introduction}

Critical realism (CR) in contemporary management research is embedded within a wider intellectual trend within social science and the humanities (Reed 2005). It derives mainly from the work of Bhaskar $(1978,1993,1979)$ and has also been developed by other scholars like Archer (1995), Sayer (1992, 2000) and Fleetwood (2005, 2004). Having gained prominence over the last 30 years, CR as a philosophical position originated in natural science and has been increasingly applied in various fields of social science (Blundel 2007; Easton 2010). In management studies, it has been used to explore competing theories and to explain complex social events in the fields of information systems and organisation studies (Delbridge and Edwards 2013; Volkoff and Strong 2013; Belfrage and Hauf 2017). It has also been increasingly adopted by entrepreneurship scholars (Martin and Wilson 2014; Kitching, Hart, and Wilson 2015; Lee and Jones 2015; Ramoglou and Tsang 2015). However, there is still a lack of empirical work that directly employs CR methodologies, especially its distinct mode of analysis: namely, retroduction.

The purpose of this paper is to critically review how the methodological principles for conducting CR-based research can be applied in empirical studies and to develop a case study research design to guide empirical research in entrepreneurship. I examine the core ontological assumptions and methodological implications of CR, including its stratified ontology, causality and retroduction. I then use the conceptual debate on entrepreneurial opportunities as an example to discuss how a CR-based research design can provide comparative explanatory power to assess competing theories and to reveal the underlying structure and mechanism that generate a social event. In entrepreneurship research, the concept 'entrepreneurial opportunity' is seen as one of the key and unique domains of entrepreneurship 
(Busenitz et al. 2003; Venkataraman 1997; Alvarez, Barney, and Young 2010). However, despite the rapidly growing literautre on this topic, there are continuing debates and competing views about the objectivity and subjectivity of the concept (Alvarez, Barney, and Young 2010; Suddaby, Bruton, and Si 2015), which makes it still theoretically and empirically elusive (Davidsson 2015; Dimov 2011). CR addresses these competing views and this elusiveness through its unique stratified ontology of the three domains of reality, which links objective/unobservable social structure and subjective/observable human agency in its causal explanation.

The paper is structured as follows: I start by reviewing the core ontological assumptions of CR with a particular focus on their methodological implications. Then, I discuss the role of qualitative research methods and a case study approach in critical realist research, and propose a three-step retroductive case research design. The research design is derived from both the methodological principles and guidelines proposed in a number of studies. Next, I illustrate the meaning and practicality of the research design by drawing on a critical realist case study of entrepreneurial opportunities where competing theories are present. Finally, I conclude by discussing the contributions of $\mathrm{CR}$ and the value of the research design to empirical research in the field of entrepreneurship.

\section{Critical realism: basic assumptions and methodological implications}

CR differs from traditional philosophical paradigms because of its key ontological and epistemological assumptions or positions. By combining transcendental realism with critical naturalism, critical realists hold the view that our knowledge about the social world "is a socially produced knowledge of a natural (man-independent) thing" (Archer et al. 1998, 65). The double recognition of both an independent reality and subjective interpretations makes CR distinctive from traditional positivist (empiricist) 
and social constructionist (interpretive) paradigms (O'Mahoney and Vincent 2014). While the difference between CR and traditional philosophical paradigms is in itself an important subject, for the purpose of this paper I do not intend to provide a detailed discussion about this. This paper specifically focuses on some of the principal features of CR which are linked to the choice of a methodological approach to empirical studies in entrepreneurship. These principal features include the entity, stratified ontology, emergence, open system, causality, and retroduction. By linking these features with methodological principles, I then discuss how a CR-based research design can be developed to enable empirical investigation into a social phenomenon.

\section{Entity, stratified ontology, emergence and open system}

CR argues that reality is a stratified, open system of emergent entities (Bhaskar and Lawson 1998). Entities are “things which 'make a difference' in their own right, rather than as mere sums of their parts" (O'Mahoney and Vincent 2014, 6). Unlike 'variables' which only record or register (quantifiable) changes and do not offer causal explanations (Sayer 1992), entities have causal power and properties which can generate real effects (Easton 2010; Mingers, Mutch, and Willcocks 2013). Entities may exist in both intransitive and transitive dimensions - they can be physical, social, human, or conceptual entities (Easton 2010; O'Mahoney and Vincent 2014). Entities provide the basic building blocks for theoretical development and explanation (Easton 2010). Entities can be organised or structured at different levels. Any social event (a higher level entity) occurs when a set of internally related entities at a lower level is structured (structure) and acts in a certain way (causal power and mechanism) to generate effects (emergence). The multi-level nature of entities implies that entities can construct reality at different levels in both transitive and intransitive dimensions. 
Bhaskar (1978) illustrates this ontological position via his assumption of a stratified model of three interrelated domains of reality: the empirical, the actual and the real.

The domain of the empirical is the world of human experience of events. In $\mathrm{CR}$, this domain can be seen as human actors' observations, perceptions, and sensations of reality (Leca and Naccache 2006). Activities in this domain are perceivable; both actors and researchers can have immediate access to this domain. The domain of the actual refers to social events which are the focal objects that critical realist research investigates (Easton 2010). An event is defined as "a specific happening or action resulting from the enactment of one or more mechanisms" (Wynn and Williams 2012, 792). Events can be perceivable and then transformed into the empirical domain, but only when empirical perceptions are identified correctly through human agency, normally through abstraction from observable effects rather than direct perception (Wynn and Williams 2012). Events are the result of exercised generative mechanisms and causal powers embedded in a structure of entities in the domain of the real. Structure is defined as the distinctive inner composition of an event which consists of internally related entities (Sayer 1992). It can take many forms. Danermark et al. $(2002,47)$ suggest that the structure of a social event can be "organization structures, small groups structures, the social structures of the dyad or the triad, the structures of street life, communication structures, linguistic structures, personality structures, and so on". Causal powers are the potentials or capabilities to act that are inherent in these structures of entities (Lawson 1997), while generative mechanisms are the ways of acting or working of the structures (Bhaskar 1978). Causal powers and generative mechanisms are not necessarily observable; they exist irrespective of whether they have been exercised, detected or become manifest 
(Bhaskar 1978, 1979). It is also possible that the causal powers and mechanisms are not exercised at all.

$\mathrm{CR}$ describes the process of lower level entities generating higher level events or entities as 'emergence'. The higher level entities which have emerged from the interactions of lower entities can possess new properties which cannot be reduced to the characteristics of lower level entities (Archer 1995; Easton 2010). In social science, emergence normally occurs in an open system which is beyond our ability to directly control (Bhaskar 1979; Wynn and Williams 2012). Social events seldom occur under stable conditions in a controlled environment that allow replicated investigations; instead, the presence and configurations of social conditions are somewhat contingent (Sayer 1992). As a result, a social event "is not only dependent on the causal powers available within a social structure, but also on the continuously changing contextual conditions and the evolving properties of components within the structure" (Wynn and Williams 2012, 793).

The assumption of a multi-level emergence where the causal powers and generative mechanisms may or may not be exercised in an open system has essential methodological implications. First, given the complex nature of social reality, investigations and research restricted to a single domain tend to be unsatisfactory (Blundel 2007). Researchers pursuing CR-based research need to identify structures, causal powers or mechanisms in the deeper domain of the real (Leca and Naccache 2006) while paying attention to contingent conditions and connectedness between individuals. However, as the deeper domains are not necessarily perceivable, events can at best only be recorded or described by researchers in a way which is close to the event (Easton 2010). The epistemological relativism in CR implies that our knowledge of the social world, and our interpretations, can be fallible (Bhaskar 1998; 
Wynn and Williams 2012); therefore, our descriptions of an event may not be always entirely congruent with the event.

A second methodological implication of the stratified ontology and epistemological relativism is that different researchers may develop alternative explanations for the same social event. Depending on the conditions, the same causal powers and mechanism may produce different events, or the same event can emerge because of different causal powers and mechanisms (Sayer 1992). It is also possible that, depending on the conditions, causal powers and mechanisms are not exercised, which leads to the non-occurrence of events. Critical realists believe that the nonoccurrence of events can also provide useful insights to understand events per se (Easton 2010, 120).

Third, CR does not deny the importance of context in research. The domain of the real can be seen as a picture of "complex interaction between dynamic, open, stratified systems, both material and non-material" (Mingers, Mutch, and Willcocks 2013, 796). Because both causal powers and conditions can continuously interact with each other and change, it becomes impossible for a generative mechanism in a given system to generate the same social event in the future (Wynn and Williams 2012). In fact, any research based on CR should be contextualised (Leca and Naccache 2006). Individuals' behaviour, activities, and outcomes are conditioned by the context; therefore, CR "robustly allows for the implications of varying contextual conditions on the entrepreneur's network behavior" (Bowey and Easton 2007, 280).

Finally, CR-based research must involve some elements of connectedness. As social events emerge from the interactions of lower level entities, the social world can only be understood through the connections between individuals, rather than individuals in isolation (Easton 2010). Therefore, a critical realist explanation of why 
a social event occurs "depends on an account of how the properties and powers of the 'people' causally intertwine” (Archer 1995, 15). Likewise, the causal powers are less likely to be inherent in single entities, but more in the structure of social relations which they form (Sayer 1992). On the basis of these understandings, social scientists should not only focus on the causal powers of individuals, but they should pay more heed to the empirical importance of social interactions (Delbridge and Edwards 2013).

\section{Causality}

Critical realists hold a very distinctive view of causality. A primary objective of CRbased research is to provide empirically supported causal explanations, rather than predictions, of how and why events occur (Wynn and Williams 2012). Here, causality focuses on the causal powers that enable what can happen, but does not predetermine what will happen (Sayer 1992). CR's transcendental realist root acknowledges that there is a reality independent of human interpretations and not all the entities in the three domains of reality can be directly observed by researchers. As a consequence, repeated observations which only focus on the observable entities have little to do with the real causes of social events. In other words, the CR-based causal explanation is not about the deterministic regularity of patterns of observations or experiences, but about the tendency or possibility for certain causal powers and mechanisms to exist and how the underlying structures affect outcomes in a specific context (Sayer 1992; Tsoukas 1989; Wynn and Williams 2012). However, this does not mean that we, as researchers, cannot reveal the domain of the real of a social event through observations. In CR, knowledge of the causal powers and generative mechanisms is not always based on our abilities to directly observe them, but can be based on our abilities to observe their effects (Bhaskar 1978). Through the observation of the effects, we can use our intellectual and perceptual skills to form our beliefs or 
conjectures about the existence of the structures, causal powers and mechanisms in the domain of the real (Bhaskar 1978; Zachariadis, Scott, and Barrett 2010). Therefore, although CR rejects the idea that causality is based on repeated observations, it does acknowledge that "observability may make us more confident about what we think exists" (Sayer 2000, 12).

\section{Retroduction}

$\mathrm{CR}$ adopts a distinctive form of inference called retroduction which posits that events are explained through identifying and hypothesising causal powers and mechanisms that can produce them (Bhaskar 1978; Sayer 1992). This explanatory approach requires very different methodological features to those in inductive and deductive research (Blundel 2007). In general, induction requires moving from a number of similar observations to empirical generalisations and theories, while deduction adopts a top-down approach that moves from general theories and existing variables to a conclusion about these variables' implications in repeated empirical observations. Both approaches rely on repeated observations or patterns of empirical events that can only provide inadequate information about the real causes of social events. Retroduction requires researchers to move from empirical experiences and descriptions of an unexplained event (domain of the empirical) to a deeper level of causal powers and mechanisms (domain of the real) which makes the phenomenon possible (Zachariadis, Scott, and Barrett 2013; Volkoff, Strong, and Elmes 2007). In practical terms, a retroductive study requires at least two things: 1) explication of the focal event (domain of the actual) from empirical observations and, 2) a hypothesis of the existence of causal powers, mechanisms and their underlying structures that are not subject to direct observation. This gives CR ontological depth and makes it 
possible to not only understand what things are different, but also how things could have been different.

First, CR holds that the description and explication of social events are the foundations of any research analysis (Wynn and Williams 2012). To understand the nature of an object under study, researchers have to select and abstract the constituents of the focal event, normally from experience (Sayer 1992). In order to find out those properties really related to the focal event, critical realist abstraction is built around a key principle called natural necessity, where relations between entities are categorised as substantial and formal, internal and external, and symmetrically and asymmetrically necessary (Danermark et al. 2002; Blundel 2007). Researchers have to identify and specify those internal and necessary relations from experiences, and separate them from external and contingent relations (Danermark et al. 2002).

Second, as the domain of the real is not always directly observable, researchers have to propose hypothetical structures, causal powers and generative mechanisms which can explain the focal phenomenon (Bygstad 2010; Zachariadis, Scott, and Barrett 2013). The CR position on causality requires a distinctive view on developing hypotheses in theory building. In CR, hypotheses are developed to identify and posit possible structures and causal mechanisms for social events, and they do not include predicted or generalised events. The goal is to posit structures and causal mechanisms that, if they existed and acted in the postulated manner, could function as a causal explanation for the events (Sayer 1998). Accordingly, theory building is not an abstruse way of describing experiences, but a way of referring to these hypotheses of the focal events, which can be either confirmed or falsified by experiences (Bhaskar 1978). 
Developing hypotheses in retroductive studies relies on researchers' intellectual and perceptual skills (Bhaskar 1978; Zachariadis, Scott, and Barrett 2010). An important methodological implication is that, as human knowledge is always fallible, there are always possibilities that the hypotheses will not generate expected effects in the open social system, and different researchers may also provide competing explanations and theories for the same social event. Thus, researchers should aim to carry out empirical research to eliminate or support some of the alternative explanations, and to eliminate false hypotheses by testing the effects of the hypotheses empirically.

Mingers, Mutch, and Willcocks $(2013,797)$ summarise the retroductive methodology as 'DREI': "describe the events of interest; retroduce explanatory mechanisms; eliminate false hypotheses; identify the correct mechanisms." This is the methodology I follow in this study. The rest of this section discusses what methods are suitable for this study and the research steps based on the DREI methodology.

\section{Research methods and the process of CR-based research}

\section{The role of qualitative research methods}

It has been widely argued that CR-based research embraces both qualitative and quantitative methods (Zachariadis, Scott, and Barrett 2013; Wynn and Williams 2012; Easton 2010). However, in CR the rejection of positivist preoccupations with prediction and quantitative measurement necessitates a preference for qualitative methods in understanding social events (Ackroyd and Fleetwood 2000). In practical terms, the difficulty of using quantitative methods in CR lies in the question of what kind of research objects can be quantified. Sayer (1992) argues that practically adequate forms of quantifying an object can only be achieved when the object is 
'qualitatively invariant'. In other words, the object can be broken up and recombined without affecting its nature; it can be measured regardless of time and space and we know that we are measuring the same thing. However, these scenarios are more likely to occur in a closed system rather than an open system. In the field of entrepreneurship, a similar view is also held by scholars who complain that "the 'numbers' do not seem to add up to what would seem to be a coherent story of what we believe to be the nature of entrepreneurship" (Gartner and Birley 2002, 388).

The use of qualitative methods in CR-based research is more established. Zachariadis, Scott, and Barrett (2013) argue that qualitative methods are 'epistemologically valid' as they are more capable of describing a social phenomenon and producing situated analytical explanations. The social world consists of multiple and dynamic relationships in an open system where human agency plays a determining role (Sayer 2000). Because of the existence of unidentified conditions, tacit skills, unconscious intentions and consequences in human agency, the interpretation and understanding of human actions become essential in understanding a social event; hence the preference for qualitative methods. Furthermore, as qualitative methods involve less closure than quantitative methods (Zachariadis, Scott, and Barrett 2013), they allow researchers to ask open-ended questions, generate new insight and build new theories without being constrained by "ideational ruts and cul-de-sacs of prior theories" (Suddaby, Bruton, and Si 2015, 2).

\section{Critical realism and case study}

Although Bhaskar does not recommend a specific research method, a case study approach is often considered to be the best research method to use when conducting critical realist research (Wynn and Williams 2012; Easton 2010; Kessler and Bach 2014). For example, Danermark et al. (2002) suggest that qualitative methods in CR 
can be summarised as having four principal features: a case study design, a study of the cases in their context, emphasis on understanding, and the generation of theories. In general, a case study approach is particularly useful in explanatory research which addresses 'how' and 'why' questions (Yin 2009) in an attempt to understand complex and dynamic relations and interactions within single or multiple settings (Eisenhardt 1989). It is well suited to CR-based research that is intended to explore social events in contexts and to reveal underlying causal powers and mechanisms that reflect the complex interaction between structure and agency (Kessler and Bach 2014).

\section{A three-step research process involving retroduction}

As discussed earlier, the primary objective of CR-based research is to provide causal explanations at different levels by uncovering mechanisms and underlying structure, based on perceptions of empirical events (Volkoff and Strong 2013; Wynn and Williams 2012). Achieving this involves a creative process with various phases and activities (Zachariadis, Scott, and Barrett 2013). There are a number of studies which propose various research designs, guidelines and sequences of research actions implementing the DREI methodology (Zachariadis, Scott, and Barrett 2013; Wynn and Williams 2012; e.g. Danermark et al. 2002). While there is not a dominant research design, I identify three research activities as the most important research steps in these studies: explication of events, retroduction, and empirical corroboration. These research activities are fundamental ideas based on the originating concepts of $\mathrm{CR}$, which can be used to assist researchers in conducting CR-based case research.

The first step, explication of events, focuses on the description, identification and abstraction of the composite social events under study. It starts in the domain of the empirical (Danermark et al. 2002). A detailed and thorough description of the observed experiences is essential for identifying social structure, agency and the 
context, which are causally related; this description serves as a foundation for understanding what really happens in the social events (Wynn and Williams 2012). Researchers can describe the composite events by making use of everyday concepts such as experiences which can be perceived by everyone. However, because social events occur in a complex open system, it is impossible for individuals to examine every possible aspect or constituent of a social event. Therefore, researchers have to make a decision to identify and select certain components of the social events, in addition to choosing sources of data and determining how to conduct analysis (Zachariadis, Scott, and Barrett 2013). In a qualitative case study, the sources of data can be interviews, observations and archives (Eisenhardt 1989). The empirically observed, identified and selected experiences are then abstracted to allow researchers to describe and explicate the events that we believe to have occurred (Wynn and Williams 2012). Here, research activities move from the domain of the empirical to the domain of the actual. This research step can be informed by existing theories in the relevant field of interest, which helps researchers to shape the theoretical description of the social event (Zachariadis, Scott, and Barrett 2013).

The second step, retroduction, involves hypothesising about the causal powers, mechanisms or structures that possibly generate the focal social event (Zachariadis, Scott, and Barrett 2013). Specifically, researchers interpret and theoretically redescribe the selected aspects of the social event and develop hypotheses about social structures, causal powers and generative mechanisms that are used in the following step of the empirical investigation. This phase of research activity starts with asking the question: "What is it about the structures which might produce the effects at issue?" (Sayer 1992, 95). To do this, researchers need to identify - normally from participants' own experiences - different aspects of social 
and physical structures and the contextual environment which are causally relevant and bring them into theoretical perspective (Williams and Karahanna 2013). The term 'causally relevant' means that the social structure which researchers aim to identify should not only be useful in potentially explaining the social events, but should also be comprehensible and durable. According to Sayer $(1992,95)$, durable social structures are "those which lock their occupants into situations which they cannot unilaterally change and yet in which it is possible to change between existing positions". This research step then requires researchers to identify and elaborate on causal powers inherent in the identified social structure. It also requires researchers to link the causal power to the social event under study, which helps to identify causal mechanisms (Wynn and Williams 2012). Existing theories or theoretical explanations play an essential role during this process. Wynn and Williams (2012) suggest that retroduction is a creative research process where researchers may develop or propose multiple explanations. As human knowledge is always theory-laden (Sayer 1992), different theories "can and should be presented, compared and possibly integrated with one another" in order to develop the hypotheses (Danermark et al. 2002, 110). However, because human knowledge is also fallible (Sayer 1992), one theory may not always be sufficient to explain the social event under study. Sometimes, it requires different complementary theories to be tested empirically in order to achieve analytical stability of the explanatory power of hypotheses (Danermark et al. 2002). In fact, CR insists that "it is possible, indeed necessary, to assess competing scientific theories and explanations" (Reed 2005, 1630) as it provides comparative explanatory power to reveal the underlying structure and mechanism that generate the focal event. Therefore, this phase of research is likely to consist of "thought trials" (Weick 1989) 
which involve constant comparison and iterative reflection between the literature, data, and hypotheses (Zachariadis, Scott, and Barrett 2013).

The last step, empirical corroboration, examines and tests the hypothetical structures and mechanisms through empirical scrutiny and compares these to competing explanations in order to achieve empirical adequacy (Bhaskar and Lawson 1998). The main purpose of this step is to use empirical data to ensure that the hypotheses have adequate causal depth and explanatory power which represent the reality of the focal event at different levels (Wynn and Williams 2012). Hypotheses about the structures, powers and mechanisms developed earlier are interpreted, verified and assessed in an empirical context (Danermark et al. 2002; Zachariadis, Scott, and Barrett 2013). While these hypotheses may not be directly observable, researchers can still form beliefs in their existence through the observation of their effects (Bhaskar 1978). In research practice, the effects can be examined by assessing multiple participants' experiences and perspectives of the observed events, and by evaluating to what extent the hypotheses can be supported across multiple participant experiences and perspectives (Wynn and Williams 2012). Another important part of empirical corroboration is to affirm that the hypotheses have better explanatory power than alternative explanations (Wynn and Williams 2012). As supplementary theories may be used in the retroduction process, it is the researcher's task to check which explanation is the most accurate in the given context (Bhaskar 1978), to identify conditions for which the alternative or competing explanations bear different implications on the focal event (Sayer 1998), and to critically assess or eliminate other explanations that are less empirically adequate (Zachariadis, Scott, and Barrett 2013). 
These three research steps provide a practical guide for carrying out CR-based empirical research. However, these methodological principles do not suggest a linear, step-by-step research procedure. Rather, any critical realist research involving these steps should be considered to be an iterative process of data collection and analysis (Williams and Karahanna 2013; Zachariadis, Scott, and Barrett 2013).

\section{An example of applying CR to entrepreneurship research: an exploratory study on entrepreneurial opportunities in China}

In this section, I provide an example of a qualitative case study in entrepreneurship, using $\mathrm{CR}$ as the underlying philosophy and demonstrating its methodological implications in research practice. In entrepreneurship research, the central position of the concept 'entrepreneurial opportunity' has stimulated long-lasting debates on whether entrepreneurial opportunities are objective phenomena formed by social and economic disequilibria or an enactment of entrepreneurs' subjective beliefs and actions (Alvarez, Barney, and Young 2010; Suddaby, Bruton, and Si 2015). In addition, implicit in the current empirical studies on this topic is mainly a narrative of entrepreneurs as alert individuals, who assume that entrepreneurial opportunities are 'out there', which renders the concept largely an empirically elusive construct (Dimov 2011; Short et al. 2010). CR addresses these competing views and this elusiveness through its unique stratified ontology of the three domains of reality, which links objective/unobservable social structure and subjective/observable human agency in its causal explanation. I use the three-step retroductive process discussed above to illustrate how this can be achieved through revealing the deeper reality of an entrepreneurial opportunity - namely, its social structure, causal powers and generative mechanisms. 


\section{An overview of opportunity research in entrepreneurship}

The objectivity vs. subjectivity debates in the entrepreneurship field focus on a fundamental question: are entrepreneurial opportunities objective realities or enactments of entrepreneurs' subjective visions? The debates are dominated by two competing causal explanations; i.e., the discovery view and the creation view, based on a realist and a social constructionist ontological position, respectively (Alvarez, Barney, and Young 2010). The main ontological assumption of the discovery view is that unobservable opportunities exist objectively, independent of and prior to the individual perception process (Korsgaard 2011; Baron and Ensley 2006).

Entrepreneurial opportunities are defined as exogenous situations where new goods, services, raw materials, markets and organising methods can be potentially introduced by innovatively alert individuals for profit (Shane and Venkataraman 2000).

Entrepreneurial opportunities are seen as objective phenomena formed by fundamental economic disequilibrium which exists independent of human cognition (Eckhardt and Shane 2010). Individuals can only perceive, recognise or identify these objective opportunities through rational decision-making processes in the form of 'conjectures', ‘business ideas' or 'means-ends frameworks' (Shane 2003; Shane 2012; Eckhardt and Shane 2013). However, this view assumes a 'God's eye view' of opportunities as reality (Alvarez and Barney 2010) as it does not clarify to what extent opportunities can be directly examined and studied at the individual level (Dimov 2011; Klein 2008).

By contrast, the creation view argues that entrepreneurial opportunities are created endogenously by individuals' subjective beliefs and actions (Alvarez and Barney 2007; Alvarez, Barney, and Young 2010; Sarasvathy et al. 2010). Based on a social constructionist ontology, entrepreneurial opportunities are considered to be a 
stream of gradually developed creative ideas (Dimov 2007), created or co-created from individuals' beliefs, aspirations, imaginations and interpretations of their external environments (Lachmann 1986; Sarason, Dean, and Dillard 2006; Sarasvathy et al. 2010). As a result, "opportunities cannot be fully understood until they exist, and they only exist after they are enacted in an iterative process of action and reaction" (Alvarez and Barney 2010, 566). This view emphasises the role of human agency in creating opportunities which are directly observable. However, a question that remains largely unanswered is to what extent actions which create opportunities can be distinguished from actions which create other entrepreneurial outcomes (such as business ventures). This problem also raises questions of validity in observing entrepreneurial opportunities empirically; that is, whether our empirical observation is indeed oriented toward entrepreneurial opportunities (Dimov 2011).

\section{The need for a critical realist perspective}

The above debates offer two competing causal explanations that either stress the influence of structure over agency or vice versa. CR reconciles the debates by providing a useful philosophy that accounts for both unobservable structure and observable agency equally as part of a causal explanation (Blundel 2007; Martin and Wilson 2014). CR carefully separates structure and agency by considering them to be two ontologically different but related domains of reality (Leca and Naccache 2006; Danermark et al. 2002). In CR, human agency always occurs in a pre-structured social world. Bhaskar (1998) suggests that human agency is always conditioned by structural possibilities and constraints that it does not produce, but it also reproduces social structure. Therefore, social structure is both the ever-present condition and the outcome of human agency. This separation allows us to logically discuss their 
interactions and effects on each other (Volkoff, Strong, and Elmes 2007), which also sets CR apart from structuration theory (Mole and Mole 2010).

On the basis of this understanding, the 'exogenous shocks' or economic disequilibrium discussed in the entrepreneurship literature can be considered as a social structure produced by human agency, while also providing conditions for human agency to act upon, which are all part of the reality of entrepreneurial opportunities. Therefore, from a CR perspective, an entrepreneurial opportunity exists as a propensity that, when actualised through human agency, can manifest itself as a profitable product or service that fulfils market demands (Ramoglou and Tsang 2015). Furthermore, as structures are nested in structures, the social structures underlying the emergence of entrepreneurial opportunities can exist at different levels (Danermark et al. 2002). These can be considered the social structure where human agency is embedded, or contextual conditions which provide constraints or possibilities for human agency, or the outcomes of human agency at a higher level.

\section{A CR-informed explanatory research design}

Step one: explication of events

This research step involves the description of entrepreneurial opportunities based on the participants' experiences and the theoretical re-description and abstraction of opportunities as an abstract social event. The empirical challenge here is that entrepreneurial opportunities, as propensities, are not easy to study, observe or conceptualise. However, we can still perceive their existence through observation of their effects (Bhaskar 1978; Zachariadis, Scott, and Barrett 2013). Ramoglou and Tsang (2015) suggest that entrepreneurs can make cognitive contact with opportunities in two ways: 1) entrepreneurs can form imagination and beliefs about a 
profitable state of the world after engaging in a course of entrepreneurial actions, but before the realisation of profits; and 2) entrepreneurs know retrospectively that opportunities existed after the realisation of profits. These arguments provide a set of observable phenomena which allow us to empirically examine the existence of opportunities before and after their actualisation. The actualisation of entrepreneurial opportunities begins with venture ideas where entrepreneurial imagination and beliefs are formed and evolve. However, venture ideas alone cannot be considered as entrepreneurial opportunities (Venkataraman et al. 2012) until the entrepreneur acts in the real world. Accordingly, entrepreneurial actions of pursuing seed venture ideas can be seen as empirical footprints of opportunities (Dimov 2011). Finally, entrepreneurial opportunities can be seen as a vision of future market relationships where profits are realised (Dimov 2011). Thus, the actualisation of entrepreneurial opportunities can be empirically examined through the development of market exchange relationships.

As discussed earlier, critical realist abstraction is built around a key principle called natural necessity, where researchers have to separate internal and necessary relations from external and contingent relations (Danermark et al. 2002). When analysing the empirical data, the abstraction of entrepreneurial opportunities requires the identification of internal and necessary entities and the removal of external and unnecessary entities from experienced opportunities described at the earlier stage. The analysis focuses on a question: "What cannot be removed without making the object (i.e., opportunities) cease to exist in its present form?" (Danermark et al. 2002, 47). To answer this question, I use a comparative case analysis approach which is guided by a critical realist grounded theory process, as suggested by Kempster and Parry (2011) (Figure 1). When informed by CR, the grounded theory method allows us to 
conduct hierarchical analysis from empirical data to codes, themes and a higher level of abstraction. Therefore, grounded theory analysis complements well the abstraction in this study, which requires moving from the experiences (domain of empirical) to the abstract of entrepreneurial opportunities (domain of actual). It is, however, important to note that, in this study, grounded theory should only be treated as a data analysis method underpinned by CR ontology, rather than a separate research methodology that follows a restrictive set of rules.

[Insert Figure 1 here]

As shown in Figure 1, the data analysis begins with the identification of clusters of meanings based on the participants' description of their experiences of entrepreneurial opportunities, such as how to develop seed venture ideas and market exchange relationships. CR claims that participants' everyday knowledge and concepts should be treated as the very starting point of the research process in analysing and explaining a social event. However, as researchers, we must also surpass these everyday concepts and survey them in theoretical form in order to generate new knowledge (Danermark et al. 2002). Thus, the next step of data analysis involves organising these everyday concepts by theoretical themes, which then become a set of integrative categories. The theoretical concepts in both theoretical views discussed earlier are considered. The identification of themes and integrative categories involves an iterative process of data collection, coding, analysis, and adjustment. Comparative case analysis is used at different stages of the process. First, I compare different descriptions of experienced opportunities based on the two competing views, which results in the elimination of entities that have formal relations with entrepreneurial 
opportunities, such as age, gender, and industry. Second, I compare the clusters of meanings across different cases, which results in the removal of external relations that are relevant but contingent upon the existence of entrepreneurial opportunities. For example, entrepreneurial alertness has been found to be important in some cases, but not others; it is therefore not necessary for the existence of opportunities and can only be considered as an external entity. Finally, I also compare and summarise themes, which results in the definition of major integrative categories which describe the abstraction of 'entrepreneurial opportunity'.

\section{Step two: retroduction}

The second step, retroduction, involves "hypothesizing about the possible mechanisms or structures capable of generating the phenomena that have been observed, measured, or experienced" (Zachariadis, Scott, and Barrett 2013, 866). Starting with the question "What is it about the structures which might produce the effects at issue?" (Sayer 1992, 95), this research step aims to provide preliminary causal explanations of the emergence of entrepreneurial opportunities. Existing theories play an essential role in this retroduction process. Wynn and Williams (2012) suggest that retroduction is a creative research process whereby researchers may develop or propose multiple theoretical explanations. Therefore, it is essential for researchers to evaluate and compare the explanatory power of different theoretical explanations and, finally, to select theories which most accurately represent the 'domain of real' given our existing knowledge. This is described as judgemental rationality in CR (Bhaskar 1998). Despite the subjective nature of theory selection, Walsham (2006) suggests that there are still some general guidelines that researchers should follow when selecting theories. According to him, researchers should choose theories which they feel are most insightful based on their own research interests, 
experiences and backgrounds, and on whether the theories are relevant to the research topic and the empirical data.

Following these guidelines, a pilot study is carried out to explore the potential existence of social structures, causal powers, and generative mechanisms which lead to the emergence of entrepreneurial opportunities. As a result, I develop an initial hypothetical framework where guanxi, the Chinese version of social networks, is considered to be the social structure, while social capital is considered to be the inherent causal power in guanxi (Figure 2). In the field of entrepreneurship, there is a growing consensus that the interplay between individuals and network structures could drive the emergence of opportunities (Gedajlovic et al. 2013). The combination of guanxi and social capital perspectives, as causally relevant social structure and causal power, add new insights to the explanation of the emergence of entrepreneurial opportunities. The hypothetical framework is then continuously developed, revised and tested during the rest of the study. It also involves constant comparison and iterative reflection between the literature, data, and hypotheses (Zachariadis, Scott, and Barrett 2013).

Figure 2 shows that the hypothetical framework consists of three hypotheses. The first hypothesis is that guanxi is a basic and durable social structure that leads to the emergence of entrepreneurial opportunities. According to Sayer $(1992,95)$, durable social structures are "those which lock their occupants into situations which they cannot unilaterally change and yet in which it is possible to change between existing positions". Guanxi plays a similar role in Chinese society. Described as both interpersonal connections and an underlying philosophy, guanxi refers to pervasive social networks that dominate every person's social life and every aspect of Chinese society (Zhang and Zhang 2006; Park and Luo 2001). It can be proactive and 
predetermined (Wank 1996), because individuals can play a proactive role in exchanging favours with others based on their own interests, but it is also unlikely for people to unilaterally change some guanxi, such as family ties. Therefore, the development of an entrepreneurial opportunity may at least partly depend on the guanxi ties which the entrepreneur trusts, and any analysis of the opportunity is incomplete unless we consider the role of these ties (Chell 2007). The selection of guanxi as a durable social structure is also suitable for critical realist studies. Lee and Jones (2008) argue that social networks across society can influence individuals' actions through generative mechanisms, such as the effects of network configurations; therefore, "all network research adopts 'some version of critical realism"” (ibid: 567). Another hypothesis in the framework is that social capital is the inherent causal power in guanxi which can be unexercised or exercised under certain conditions (Light and Dana 2013). Social capital theory suggests that an agent's embeddedness in social structures endows her with social capital that can provide access to information and opportunities (Anderson and Jack 2002). However, unlike actual resources that are readily available, social capital can be potential (having social capital) or mobilised (using social capital) (Kwon and Adler 2014). For example, strong ties may remain 'latent and dormant' within a network unless they are exercised and manifested through actions (Jack 2005). This is in line with the conceptualisation of causal powers as exercised or unexercised capabilities (Fleetwood 2009; Bhaskar 1978).

Finally, as causal powers, social capital acts as an enabler that represents a capability and means to engage with other agents, and, depending on the context, social capital can be either productive or detrimental to entrepreneurial actions (McKeever, Anderson, and Jack 2014). Here, social capital can be seen as a medium 
for access to entrepreneurial resources rather than a particular type of resource (Bowey and Easton 2007). Therefore, underlined by the critical realist ontology, the hypothetical framework contributes to a clearer understanding of the relations between individual agents, social structure and the effects of entrepreneurial actions (i.e., entrepreneurial opportunities as social events).

The choice of guanxi and social capital theory is based on the literature and my preliminary findings in the pilot study. It is also informed by my own experiences as a Chinese researcher, which help me to really understand the social dynamics in China when interpreting data. More importantly, I have selected the two theoretical perspectives because I believe that they potentially have the power to most accurately explain the emergence of entrepreneurial opportunities and that they are also suitable for use in a CR-informed study. However, because human knowledge is fallible (Sayer 1992), one theoretical explanation may not always be sufficient to explain the social event under study. Therefore, it is possible that the causal explanation suggested in this study may not be the only explanation of entrepreneurial opportunity emergence. There can always be alternative explanations, which may be explored in future research.

[Insert Figure 2 here]

\section{Step three: empirical corroboration}

This research step aims to further examine, test and revise the hypothetical framework through empirical study in order to develop a more accurate explanation of entrepreneurial opportunity emergence. In a critical realist methodology, this research step requires researchers to link causal powers to the social events under study and focus on the elements of reality that can help to identify the generative mechanisms 
(Danermark et al. 2002; Wynn and Williams 2012). In order to do this, I employ the empirical research procedures suggested by Sayer (1992). Starting with the question "How does social capital work in a particular case or different cases?", I firstly analyse how social capital works in each case. Here, social capital as the inherent causal power in guanxi is empirically examined through its three observable dimensions: namely, the structural, relational and cognitive dimensions (Nahapiet and Ghoshal 1998). The effects of different dimensions of social capital on entrepreneurial opportunity emergence are examined by assessing multiple participants' experiences and perspectives (Wynn and Williams 2012).

Second, within-case analysis and comparative multiple cases analysis were conducted to reveal the causal mechanisms. Certain template analysis techniques are employed for thematically organising and analysing the data, but they are not used as a single, clearly delineated template analysis method (King 2012). An initial template is developed for an iterative cross-case analysis based on the hypothetical framework (Figure 2) and pre-defined codes. An important issue here is to decide how extensive the template should be. In template analysis, too many pre-defined codes can prevent researchers from considering data that challenges original assumptions, while too few codes may result in the lack of a clear direction when researchers are overwhelmed by rich data (King 2012). Therefore, for the purpose of this study, codes related to social capital are pre-defined in order to show a clear direction of data analysis, while codes related to the generative mechanisms (accessing resources) are left open to allow for themes to emerge. The template is then applied to each case for a detailed analysis, followed by a comparative analysis across different cases. The case analysis is guided by two empirical questions: How does social capital take effect in entrepreneurial opportunities' emergence (identified at Step One)? What resources did the agents 
access through social capital? The effects of each dimension of social capital in and across cases are discussed and compared, including the conditions under which the effects of social capital may be influenced. The generative mechanisms are identified and summarised by identifying substantial relations between social capital and entrepreneurial opportunities during the analysis. In the course of this, inadequacies in the initial template are also revealed, which requires modification of the template, such as deleting codes which lack adequate evidence or changing the scope of codes in order to match the findings. Finally, the data analysis then leads to the identification of three generative mechanisms, two mediating conditions that cause the differences in entrepreneurial opportunity emergence across cases, and one moderating condition that affects the strength of the generative mechanism. A final theoretical framework is determined after several rounds of modification and refinement, until it is sufficiently clear and comprehensive (King 2012). It is important to note that the multifinality that CR holds indicates the existence of other causal paths through which similar outcomes may occur (Henfridsson and Bygstad 2013). Therefore, the generative mechanisms identified in this study should not be considered to be a governing law, but as a possible explanation in the current context.

\section{Discussion and conclusions}

$\mathrm{CR}$ as a viable alternative paradigm has been increasingly applied in various fields of social science (Blundel 2007; Easton 2010). In management studies, it is well suited to developing causal explanations and explaining competing theories of complex social events (Wynn and Williams 2012). It is also emerging as a useful paradigm for theory building in entrepreneurship research (Martin and Wilson 2014; Kitching, Hart, and Wilson 2015; Lee and Jones 2015; Ramoglou and Tsang 2015). However, there has been a lack of empirical work that directly employs CR methodologies, 
especially its distinct mode of analysis: namely, retroduction. Recent methodological development in CR has established guidelines for empirical research and the use of qualitative case studies has been addressed (Danermark et al. 2002; Wynn and Williams 2012; Zachariadis, Scott, and Barrett 2013). Following these guidelines, this paper illustrates a critical realist methodology by drawing on a retroductive multi-case study to uncover the causal powers, generative mechanisms, and conditions that lead to the emergence of entrepreneurial opportunities. This critical realist research design involves three research steps: explication of events, retroduction, and empirical corroboration. Within this research design, I have demonstrated how the three domains of reality of entrepreneurial opportunities can be empirically investigated and how the CR-based methodology can be useful in explaining competing theories. As a result, this paper makes three primary contributions in my attempt to conduct critical realist empirical research in the field of entrepreneurship.

First, this paper makes a contribution to the development of a rigorous qualitative research design and research methods in studying complex social events. My presentation of the three research design steps captures the essence of what is needed for empirical research informed by CR. Based on CR's core ontological and methodological assumptions, this research design emphasises the importance of abstraction and retroduction in the methodology to establish causal links between the domains of the real, the actual and the empirical. It, therefore, demonstrates the unique potential of the critical realist methodology to ascribe causality in open systems. This research design also allows for the use of diverse data collection and analysis techniques in empirical studies, including critical realist abstraction based on grounded theory principles and comparative analysis using template analysis techniques. Although these specific methods are likely to vary depending on the 
context of each research project, this research design can establish a clear path for new researchers to assess or develop theories in their own fields.

Second, this paper illustrates how the use of CR-informed research can be used to accommodate or explain competing theories and generate new theories. In $\mathrm{CR}$, theory generation depends on the retroduction process, where hypotheses of causal powers and generative mechanisms are developed and assessed through empirical investigation (Danermark et al. 2002). Existing theories play an essential role in this process as they shape the theoretical description of social events (Zachariadis, Scott, and Barrett 2013) and inform researchers' selection and evaluation of the explanatory power of possible theoretical explanations (Wynn and Williams 2012). As a result, using a critical realist methodology can fruitfully assess or challenge existing theories in the field and allow for more complete and effective theoretical explanations. In the research design, competing views on entrepreneurial opportunities are assessed through empirical examination and detailed description, and the differences between them can be explained through the inclusion of conditions in the theoretical framework developed. Therefore, this study not only contributes to a comprehensive understanding of entrepreneurial opportunities because it examined them in all of the three domains of reality, but it also provides a universal, critical realist, causal explanation for different outcomes observed from various theoretical perspectives. As a result, this study encompasses more aspects of entrepreneurial opportunities than the existing literature in entrepreneurship.

Finally, this paper addresses some of the empirical challenges that entrepreneurship scholars face in the study of opportunities. As discussed earlier, current empirical approaches to examining opportunities represent a fairly narrow aspect of opportunity as a much broader and more complex social event. 
Entrepreneurship researchers are confronted with some empirical challenges, such as the validity of whether what is empirically examined reflects the actual social event of opportunity (Dimov 2011). This paper helps to tackle these challenges using a critical realist conceptualisation, where entrepreneurial opportunities are seen as propensities that can be empirically examined through a set of observable phenomena before and after their actualisation. Empirically, this opens the door to explicit and direct focus on the data that is specifically relevant to entrepreneurial opportunities.

Entrepreneurship researchers, therefore, can use this work to examine entrepreneurial opportunities in individual cases or compare and contrast opportunities in different cases.

The results of this study have demonstrated that CR can provide a useful methodology to explain complex social events, such as entrepreneurial opportunities. I believe that $\mathrm{CR}$ will continue to gain acceptance in entrepreneurship research and other research fields because of its potential for theory building based on its unique ontology and causal explanations. The research design and methodological implications of CR that I have advanced in this paper may provide useful insights for subsequent entrepreneurship researchers who wish to pursue new research opportunities. Future research can extend or, where appropriate, replace the causal explanations of entrepreneurial opportunities proposed in this study. CR does not seek generalisation, because social events occur in an open system and human knowledge is essentially fallible (Sayer 1992; Wynn and Williams 2012; Kempster and Parry 2011). Therefore, I do not claim that the explanatory framework proposed in this study should be considered to be the only explanation of entrepreneurial opportunity emergence, nor that it has fully explained every aspect of the complex social event. It only serves as a possible explanation in the context of China, which may require 
further refinement or falsification; there will always be alternative explanations which should be explored in future research. For example, this study offers a critical realist explanation from a guanxi/social capital perspective in the context of China. This explanation is related to entrepreneurs' external capabilities. However, it has not paid much attention to entrepreneurs' intellectual capital and internal capabilities, which may provide alternative explanations of entrepreneurial opportunity emergence at an individual level (Puhakka 2011). The geographic context in this study is also limited to China, leaving other countries open for further investigation. However, this does not imply that the research design and the explanatory framework proposed in this study should be discredited. I believe this study offers clear guidance, which makes the study of entrepreneurial opportunities from other perspectives or in other geographic contexts in order to discover alternative explanations more practicable. In this regard, researchers should identify new or different structures, their causal powers, generative mechanisms and conditions which contribute to the emergence of opportunities. I hope the research design proposed in this study will also encourage researchers to employ CR-informed empirical studies to explore other research designs, and to encourage greater understanding and acceptance of this emerging paradigm in entrepreneurship research. 
Figure 1. The Process of Abstraction in this Study

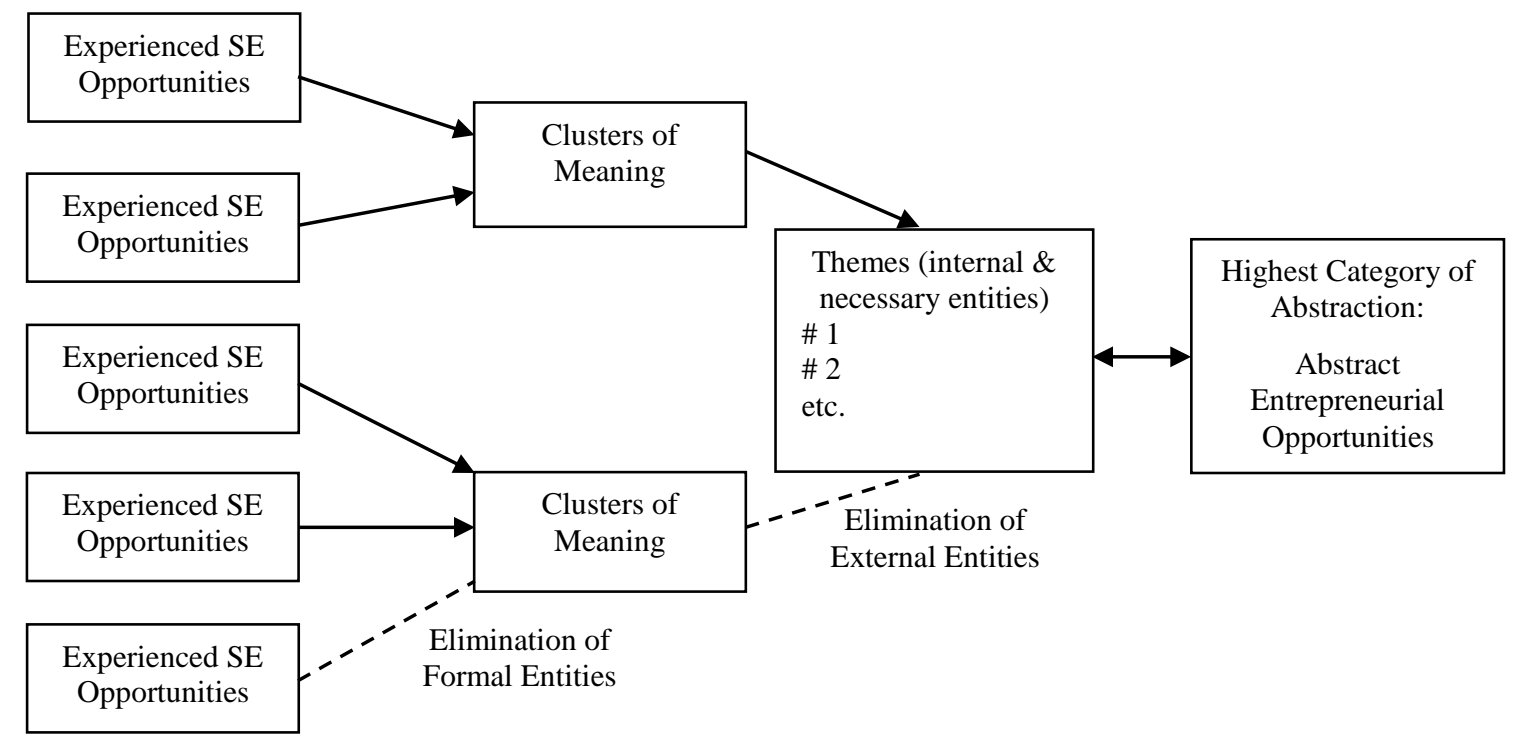

Source: revised from Kempster and Parry $(2011,116)$

Figure 2. A Hypothetical Causal Explanation of Opportunity Emergence

\begin{tabular}{|c|c|c|}
\hline Domain of Real & $\begin{array}{l}\text { Contextual } \\
\text { Conditions }\end{array}$ & Domain of Actual \\
\hline & & Experienced SE \\
\hline $\begin{array}{c}\text { Guanxi } \\
\text { (Social Capital) }\end{array}$ & $\begin{array}{l}\text { Accessing } \\
\text { Resources }\end{array}$ & (Domain of Empirical) \\
\hline $\begin{array}{c}\text { Social Structure } \\
\text { (Inherent Causal Power) }\end{array}$ & $\begin{array}{l}\text { Generative } \\
\text { Mechanism }\end{array}$ & $\begin{array}{c}\text { SE Opportunities } \\
\text { (Abstract Social Event) }\end{array}$ \\
\hline
\end{tabular}




\section{References}

Ackroyd, Stephen, and Steve Fleetwood. 2000. Realist perspectives on management and organisations. London: Routledge.

Alvarez, Sharon A, Jay B Barney, and Susan L Young. 2010. "Debates in entrepreneurship: Opportunity formation and implications for the field of entrepreneurship." In Handbook of entrepreneurship research, edited by Zoltan J. Acs and David B. Audretsch, 23-45. New York: Springer.

Alvarez, Sharon A., and Jay B. Barney. 2007. "Discovery and creation: alternative theories of entrepreneurial action." Strategic Entrepreneurship Journal 1 (12):11-26. doi: 10.1002/sej.4.

. 2010. "Entrepreneurship and Epistemology:The Philosophical Underpinnings of the Study of Entrepreneurial Opportunities." The Academy of Management Annals 4 (1):557-83. doi: 10.1080/19416520.2010.495521.

Anderson, Alistair R., and Sarah L. Jack. 2002. "The articulation of social capital in entrepreneurial networks: a glue or a lubricant?" Entrepreneurship \& Regional Development 14 (3):193-210. doi: 10.1080/08985620110112079.

Archer, Margaret, Roy Bhaskar, Andrew Collier, Tony Lawson, and Alan Norrie. 1998. Critical realism: Essential readings. London: Routledge.

Archer, Margaret Scotford. 1995. Realist social theory: The morphogenetic approach. Cambridge: Cambridge university press.

Baron, Robert A, and Michael D Ensley. 2006. "Opportunity recognition as the detection of meaningful patterns: Evidence from comparisons of novice and experienced entrepreneurs." Management Science 52 (9):1331-44.

Belfrage, Claes, and Felix Hauf. 2017. "The Gentle Art of Retroduction: Critical Realism, Cultural Political Economy and Critical Grounded Theory." Organization Studies 38 (2):251-71. doi: 10.1177/0170840616663239.

Bhaskar, Roy. 1978. A realist theory of science. Brighton: Harvester-Wheatsheaf. 1979. The possibility of naturalism: A philosophical critique of the contemporary human sciences. Brighton: Harvester. 1993. Dialectic: The pulse of freedom. London: Verso. 
1998. "General introduction." In Critical realism: Essential readings, edited by Margaret Archer, Roy Bhaskar, Andrew Collier, Tony Lawson and Alan Norrie, ix-xxiv. London: Routledge.

Bhaskar, Roy, and Tony Lawson. 1998. "Introduction: Basic texts and developments." In Critical realism: Essential readings, edited by Margaret Archer, Roy Bhaskar, Andrew Collier, Tony Lawson and Alan Norrie, 3-15. London: Routledge.

Blundel, Richard. 2007. "Critical realism: A suitable vehicle for entrepreneurship research?" In Handbook of qualitative research methods in entrepreneurship, edited by Helle Neergaard and John Parm Ulhøi, 49-74. Cheltenham: Edward Elgar.

Bowey, J. L., and G. Easton. 2007. "Entrepreneurial social capital unplugged: An activity-based analysis." International Small Business Journal 25 (3):273306. doi: 10.1177/0266242607076528.

Busenitz, Lowell W, G Page West, Dean Shepherd, Teresa Nelson, Gaylen N Chandler, and Andrew Zacharakis. 2003. "Entrepreneurship research in emergence: Past trends and future directions." Journal of Management 29 (3):285-308.

Bygstad, Bendik. 2010. "Generative mechanisms for innovation in information infrastructures." Information and Organization 20 (3):156-68.

Chell, E. 2007. "Social Enterprise and Entrepreneurship: Towards a Convergent Theory of the Entrepreneurial Process." International Small Business Journal 25 (1):5-26. doi: 10.1177/0266242607071779.

Danermark, Berth, Mats Ekström, Liselotte Jakobsen, and Jan Ch. Karlsson. 2002. Explaining society: Critical realism in the social sciences. London: Routledge. Davidsson, Per. 2015. "Entrepreneurial opportunities and the entrepreneurship nexus: A re-conceptualization." Journal of Business Venturing 30 (5):674-95. doi: http://dx.doi.org/10.1016/j.jbusvent.2015.01.002.

Delbridge, Rick, and Tim Edwards. 2013. "Inhabiting institutions: Critical realist refinements to understanding institutional complexity and change." Organization Studies 34 (7):927-47.

Dimov, Dimo. 2007. "Beyond the single-person, single-insight attribution in understanding entrepreneurial opportunities." Entrepreneurship Theory and Practice 31 (5):713-31. 
_. 2011. "Grappling with the unbearable elusiveness of entrepreneurial opportunities." Entrepreneurship Theory and Practice 35 (1):57-81.

Easton, Geoff. 2010. "Critical realism in case study research." Industrial Marketing Management 39 (1):118-28. doi: 10.1016/j.indmarman.2008.06.004.

Eckhardt, Jonathan T, and Scott Shane. 2010. "An update to the individualopportunity nexus." In Handbook of entrepreneurship research, 47-76. New York: Springer.

Eckhardt, Jonathan T, and Scott A Shane. 2013. "Response to the commentaries: The individual-opportunity (IO) nexus integrates objective and subjective aspects of entrepreneurship." Academy of management review 38 (1):160-3.

Eisenhardt, Kathleen M. 1989. "Building theories from case study research." Academy of management review 14 (4):532-50.

Fleetwood, Steve. 2004. "An ontology for organization and management studies." In Critical realist applications in organisation and management studies, edited by Steve Fleetwood and Stephen Ackroyd, 27-53. New York: Routledge. . 2005. "Ontology in organization and management studies: A critical realist perspective." Organization 12 (2):197-222. doi: 10.1177/1350508405051188.

_. 2009. "The ontology of things, properties and powers." Journal of Critical Realism 8 (3):343-66.

Gartner, William B., and Sue Birley. 2002. "Introduction to the special issue on qualitative methods in entrepreneurship research." Journal of Business Venturing 17 (5):387-95. doi: http://dx.doi.org/10.1016/S08839026(01)00077-5.

Gedajlovic, Eric, Benson Honig, Curt B. Moore, G. Tyge Payne, and Mike Wright. 2013. "Social capital and entrepreneurship: A schema and research agenda." Entrepreneurship Theory and Practice 37 (3):455-78. doi:

10.1111/etap.12042.

Henfridsson, Ola, and Bendik Bygstad. 2013. "The generative mechanisms of digital infrastructure evolution." MIS Quarterly 37 (3):907-31.

Jack, Sarah L. 2005. "The role, use and activation of strong and weak network ties: A qualitative analysis*." Journal of Management Studies 42 (6):1233-59.

Kempster, Stephen, and Ken W. Parry. 2011. "Grounded theory and leadership research: A critical realist perspective." The Leadership Quarterly 22 (1):10620. doi: 10.1016/j.leaqua.2010.12.010. 
Kessler, Ian, and Stephen Bach. 2014. "Comparing cases." In Studying organizations using critical realism: A practical guide, edited by Paul K Edwards, Joe O'Mahoney and Steve Vincent. Oxford: Oxford University Press.

King, Nigel. 2012. "Doing template analysis." Qualitative organizational research: Core methods and current challenges:426-50.

Kitching, J., M. Hart, and N. Wilson. 2015. "Burden or benefit? Regulation as a dynamic influence on small business performance." International Small Business Journal 33 (2):130-47. doi: 10.1177/0266242613493454.

Klein, Peter G. 2008. "Opportunity discovery, entrepreneurial action, and economic organization." Strategic Entrepreneurship Journal 2 (3):175-90.

Korsgaard, Steffen. 2011. "Entrepreneurship as translation: Understanding entrepreneurial opportunities through actor-network theory." Entrepreneurship \& Regional Development 23 (7-8):661-80.

Kwon, Seok-Woo, and Paul S. Adler. 2014. "Social capital: Maturation of a field of research." 39:412-22. doi: 10.5465/amr.2014.0210.

Lachmann, Ludwig M. 1986. The market as an economic process. New York: Blackwell.

Lawson, Tony. 1997. Economics and reality. London: Routledge.

Leca, B., and P. Naccache. 2006. "A critical realist approach to institutional entrepreneurship." Organization 13 (5):627-51. doi: $10.1177 / 1350508406067007$.

Lee, Robert, and Oswald Jones. 2008. "Networks, communication and learning during business start-up: The creation of cognitive social capital." International Small Business Journal 26 (5):559-94. . 2015. "Entrepreneurial social capital research: resolving the structure and agency dualism." International Journal of Entrepreneurial Behavior \& Research 21 (3):338-63. doi: doi:10.1108/IJEBR-02-2014-0025.

Light, Ivan, and Léo-Paul Dana. 2013. "Boundaries of social capital in entrepreneurship." Entrepreneurship Theory and Practice 37 (3):603-24. doi: 10.1111/etap.12016.

Martin, Lee, and Nick Wilson. 2014. "Opportunity, discovery and creativity: A critical realist perspective." International Small Business Journal:0266242614551185. 
McKeever, Edward, Alistair Anderson, and Sarah Jack. 2014. "Entrepreneurship and mutuality: social capital in processes and practices." Entrepreneurship \& Regional Development 26 (5-6):453-77.

Mingers, John, Alistair Mutch, and Leslie Willcocks. 2013. "Critical realism in information systems research." MIS Quarterly 37 (3):795-802.

Mole, Kevin F., and Miranda Mole. 2010. "Entrepreneurship as the structuration of individual and opportunity: A response using a critical realist perspective." Journal of Business Venturing 25 (2):230-7. doi:

10.1016/j.jbusvent.2008.06.002.

Nahapiet, Janine, and Sumantra Ghoshal. 1998. "Social capital, intellectual capital, and the organizational advantage." Academy of management review 23 (2):242-66.

O'Mahoney, Joe, and Steve Vincent. 2014. "Critical realism as an empirical project: A beginner's guide." In Studying organizations using critical realism: A practical guide, edited by Paul K Edwards, Joe O'Mahoney and Steve Vincent, 1-20. Oxford: Oxford University Press.

Park, Seung Ho, and Yadong Luo. 2001. "Guanxi and organizational dynamics: Organizational networking in Chinese firms." Strategic Management Journal 22 (5):455-77.

Puhakka, Vesa. 2011. "Developing a creative-cognitive model of entrepreneurial alertness to business opportunities." Journal of Management and Strategy 2 (4):85-94.

Ramoglou, Stratos, and Eric Tsang. 2015. "A realist perspective of entrepreneurship: Opportunities as propensites." Academy of management review (doi:10.5465/amr.2014.0281). (in press). doi: 10.5465/amr.2014.0281.

Reed, Michael. 2005. "Reflections on the 'realist turn'in organization and management studies." Journal of Management Studies 42 (8):1621-44.

Sarason, Yolanda, Tom Dean, and Jesse F Dillard. 2006. "Entrepreneurship as the nexus of individual and opportunity: A structuration view." Journal of Business Venturing 21 (3):286-305.

Sarasvathy, Saras D, Nicholas Dew, S Ramakrishna Velamuri, and Sankaran Venkataraman. 2010. "Three views of entrepreneurial opportunity." In Handbook of entrepreneurship research, edited by Zoltan J. Acs and David B. Audretsch, 77-96. New York: Springer. 
Sayer, Andrew. 1992. Method in social science: A realist approach. London: Routledge. . 1998. "Abstraction: A realist interpretation." In Critical realism: Essential readings, edited by Margaret Archer, Roy Bhaskar, Andrew Collier, Tony Lawson and Alan Norrie, 56. London: Routledge.

- 2000. Realism and social science. London: Sage.

Shane, Scott. 2012. "Reflections on the 2010 AMR Decade Award: Delivering on the Promise of Entrepreneurship As a Field of Research." Academy of management review 37 (1):10-20. doi: 10.5465/amr.2011.0078.

Shane, Scott Andrew. 2003. A general theory of entrepreneurship: The individualopportunity nexus. Cheltenham: Edward Elgar Publishing.

Shane, Scott, and Sankaran Venkataraman. 2000. "The promise of entrepreneurship as a field of research." Academy of management review 25 (1):217-26.

Short, Jeremy C, David J Ketchen, Christopher L Shook, and R Duane Ireland. 2010. "The concept of" opportunity" in entrepreneurship research: Past accomplishments and future challenges." Journal of Management 36 (1).

Suddaby, Roy, Garry D. Bruton, and Steven X. Si. 2015. "Entrepreneurship through a qualitative lens: Insights on the construction and/or discovery of entrepreneurial opportunity." Journal of Business Venturing 30 (1):1-10. doi: http://dx.doi.org/10.1016/j.jbusvent.2014.09.003.

Tsoukas, Haridimos. 1989. "The validity of idiographic research explanations." Academy of management review 14 (4):551-61.

Venkataraman, S., S. D. Sarasvathy, N. Dew, and W. R. Forster. 2012. "Reflections on the 2010 AMR Decade Award: Whither the Promise? Moving Forward with Entrepreneurship As a Science of the Artificial." Academy of management review 37 (1):21-33. doi: 10.5465/amr.2011.0079.

Venkataraman, Sankaran. 1997. "The distinctive domain of entrepreneurship research." In Advances in entrepreneurship, firm emergence and growth, edited by J. Katz and R. Brockhaus, 119-38. Greenwich, CT: JAI Press.

Volkoff, Olga, and Diane M Strong. 2013. "Critical realism and affordances: Theorizing IT-associated organizational change processes." MIS Quarterly 37 (3):819-34. 
Volkoff, Olga, Diane M. Strong, and Michael B. Elmes. 2007. "Technological embeddedness and organizational change." Organization Science 18 (5):83248.

Walsham, Geoff. 2006. "Doing interpretive research." European journal of information systems 15 (3):320-30.

Wank, David L. 1996. "The institutional process of market clientelism: Guanxi and private business in a South China city." The China Quarterly 147:820-38.

Weick, Karl E. 1989. "Theory construction as disciplined imagination." Academy of management review 14 (4).

Williams, Clay K, and Elena Karahanna. 2013. "Causal explanation in the coordinating process: A critical realist case study of federated IT governance structures." MIS Quarterly 37 (3):933-64.

Wynn, Donald, and Clay K Williams. 2012. "Principles for conducting critical realist case study research in information systems." MIS Quarterly 36 (3):787-810.

Yin, Robert K. 2009. Case study research: Design and methods. 4 ed. Thousand Oaks, CA: SAGE.

Zachariadis, Markos, Susan Scott, and Michael Barrett. 2010. "Exploring critical realism as the theoretical foundation of mixed-method research: evidence from the economics of IS innovations." In Judge Business School working paper series. Cambridge: University of Cambridge.

_.2013. "Methodological implications of critical realism for mixed-methods research." MIS Quarterly 37 (3):855-79.

Zhang, Yi, and Zigang Zhang. 2006. "Guanxi and organizational dynamics in China: a link between individual and organizational levels." Journal of Business Ethics 67 (4):375-92. doi: 10.1007/s10551-006-9031-7. 